\title{
Mentoring Medical Students Towards Oncology: Results from a Pilot Multi-institutional Mentorship Programme
}

\author{
Kathrine S. Rallis ${ }^{1,2}$ (D) Anna Wozniak ${ }^{1,2} \cdot$ Sara Hui $^{1,2} \cdot$ Adam Stammer $^{2} \cdot$ Cigdem Cinar $^{3} \cdot$ Min Sun $^{3} \cdot$ \\ Taylor Fulton-Ward ${ }^{3}$ - Alison A. Clarke ${ }^{4}$. Savvas Papagrigoriadis ${ }^{5} \cdot$ Apostolos Papalois $^{6} \cdot$ Michail Ch. Sideris $^{7}$
}

Accepted: 1 November 2020 / Published online: 26 November 2020

(C) The Author(s) 2020

\begin{abstract}
The mounting global cancer burden has generated an increasing demand for oncologists to join the workforce. Yet, students report limited oncology exposure in undergraduate medical curricula, while undergraduate oncology mentorships remain underutilised. We established an undergraduate oncology society-led mentorship programme aimed at medical students across several UK universities to increase medical student oncology exposure. We electronically recruited and paired oncologist mentors and medical student mentees and distributed a dedicated questionnaire (pre- and post-mentorship) to compare mentees' self-reported cancer specialty knowledge and oncology career motivation after undertaking a 6-week mentorship. We also determined students' interest across specialties and subspecialties and measured mentor availability via percentage programme uptake. Statistical analysis included univariate inferential tests on SPSS software. Twentynine (23.4\%) of 124 oncology specialists agreed to become mentors. The mentorship was completed by 30 students across three medical schools: 16 (53.3\%) Barts, 10 (33.3\%) Birmingham, and 4 (13.3\%) King's; 11 (36.7\%) mentored by medical oncologists, 10 (33.3\%) by clinical/radiation oncologists, and $9(30 \%)$ by surgical oncologists. The mentorship generated a statically significant increase in students' knowledge of the multidisciplinary team and all oncology-related specialties including academia/research but not interest towards a career in oncology. Undergraduate oncology mentoring is an effective educational, networking and motivational tool for medical students. Student societies are a valuable asset in cultivating medical student oncology interest by connecting students to faculty and increasing mentor accessibility. Further research should focus on developing an optimal mentorship structure and evaluating long-term outcomes of such educational initiatives.
\end{abstract}

\footnotetext{
Highlights of this study

- To our knowledge, this is the first UK-reported data on the value of oncology mentoring for undergraduate medical students in addition to being the first UK report of an undergraduate oncology society-led mentorship initiative.

- Data collection represented several institutions throughout the UK and encompassed various different oncology specialties and subspecialties, providing valuable insight into students' interest and the benefits of oncology mentoring in different settings.

- Our mentorship programme was successful in increasing medical students' self-reported knowledge towards all oncology specialties regardless of their allocated mentor's specialisation.

- Future work should focus on generating more opportunities for medical students to be exposed to oncology specialties; forming outcome-based guidelines for structured, systematic mentoring that will enhance its benefits; and evaluating long-term outcomes of such educational initiatives.
}

Kathrine S. Rallis

k.s.rallis@smd16.qmul.ac.uk

Extended author information available on the last page of the article 
Keywords UK medical students · Mentoring · Undergraduate oncology society · Undergraduate medical education · Undergraduate oncology teaching $\cdot$ Surveys and questionnaires

\section{Background}

Cancer remains a leading cause of premature death in the UK with one in two born after 1960 expected to be diagnosed with cancer during their lifetime [1]. The emerging cancer burden has inevitably exerted substantial strain on the United Kingdom (UK) National Health Service (NHS) generating an increasing demand for oncologist to join the workforce. This growing demand for oncologists has largely exceeded supply of trainees, evident by the threefold increase in vacant clinical oncologist consultant posts in 2017 [2]. Indeed, the total number of trainees predicted to enter the workforce in the next 5 years will not fill these vacant posts, a concerning figure attesting to the necessity for further action $[2,3]$.

Meanwhile, studies globally report limited exposure to oncology specialties in undergraduate medical education curricula [4-7], student teaching dissatisfaction with their oncology education [8] and lack of confidence with oncology care [4, 9, 10]. Furthermore, although medical mentorships confer notable benefits for both mentors and mentees, and are an established medical educational tool at trainee level [11-15], mentorships for undergraduate medical students are limited and predominantly restricted to surgery, general medicine and emergency medicine [16-18].

Notably, student interest groups, also known as undergraduate student societies, have been shown to offer valuable benefits in fostering early career interest by building studentfaculty mentorship relations and encouraging field-specific research, as demonstrated by their effectiveness across several medical specialties including oncology [16, 18-24]. Nevertheless, further work is necessary to connect medical students to oncology faculty mentors [24].

Therefore, we aimed to increase medical students' exposure to oncology specialties, including medical, clinical/ radiation and surgical oncology, through a 6-week undergraduate oncology society-led mentorship programme aimed at both pre-clinical and clinical year medical students across several UK universities.

\section{Methods}

\section{Participants}

\section{Undergraduate Oncology Societies}

Following an initial pilot mentorship programme set-up by Barts and The London (BL) Oncology Society in January
2019, all known undergraduate oncology societies in UK medical schools, equivalent to student oncology interest groups reported in Canadian and USA medical schools, were contacted via social media and email, and invited to set-up a mentorship programme at their university (September 2019). Where a medical school did not have an established undergraduate oncology society, an undergraduate medical society or medical student representative was contacted instead.

\section{Mentors}

Medical, clinical/radiation and surgical oncologists who had completed their specialty training and were senior registrars, consultants or academics based at university teaching hospitals or research institutes were identified via online search of NHS Trust and UK Cancer Institute staff directories, few recommended by personal affiliation, and contacted by email (Appendix 1) requesting their participation as mentors and outlining the potential environments (clinic, hospital and research setting) and domains (medical oncology, clinical oncology, surgical oncology and academic/clinical research oncology) in which mentees and mentors could engage in. Of those agreeing to participate, we requested their weekly timetable availability for distribution to their allocated mentee.

\section{Mentees}

Oncology societies advertised the mentorship programme to medical students at their university via mailing list and social media as well as formal university channels including year groups and newsletter. Electronic applications were received over a 10-day period. Successful applicants were determined by ranking according to objective scoring of de-identified personal statements by two independent student coordinators. A maximum of five points was allocated in each of the four domains including (a) insight into oncology career, (b) motivation, (c) previous experience and (d) signs of interest. Applicants with the highest sum of scores across both assessors (maximum 40 points) secured a mentor until no more places were left. The applicants who ranked lower and did not secure a mentor were not accepted onto the programme.

\section{Mentorship (Intervention)}

Each mentorship cycle ran over approximately 6 weeks during which period mentees were instructed to meet their mentor on 
at least three occasions to attain a certificate of completion. Mentees were required to submit an electronic pre-mentorship questionnaire prior to receiving their mentors' contact details. Mentor-mentee pairing was determined by mentor availability and students' declared interest on their application. Mentees were emailed their mentors' contact information, career description, timetable availability and hospital location with further instructions. Students were encouraged to reflect on their experience and submit an optional reflective piece for a chance at winning a book-prize award. The instructions provided to mentors and mentees (Appendix 1 and 2, respectively) were the same across all sites and specialties and ensured a relative uniformity of placements. These explained the aim of the programme, expectations, timeline and offered examples of settings in which students could shadow mentors. There was no strict curriculum as we endeavoured to allow flexibility for students to direct their learning according to their interests and aimed to tailor opportunities across the different sites. This primarily depended on mentor allocation and local facilities. The post-mentorship questionnaire was disseminated to student mentees at the end of the 6-week period. Students who did not complete the post-mentorship questionnaire were personally contacted up to three times via email to enquire why they had not done so. An extension was given to any student requiring additional time to meet their mentor. A new allocation cycle was to commence when students had finished their 6-week mentorship and mentors had become once again available for allocation to a subsequent pool of student mentee applicants (Fig. 1).

\section{Questionnaires (Intervention)}

Questionnaires were designed and compared with available ones in the literature. Discussions between research team members contributed to the final questionnaire components and design. The pre- and post-mentorship questionnaires (Appendix 3 and 4, respectively) assessed students' responses in two domains including their perceived oncology-related interest and knowledge, while a third and fourth section focused on reflection and feedback.

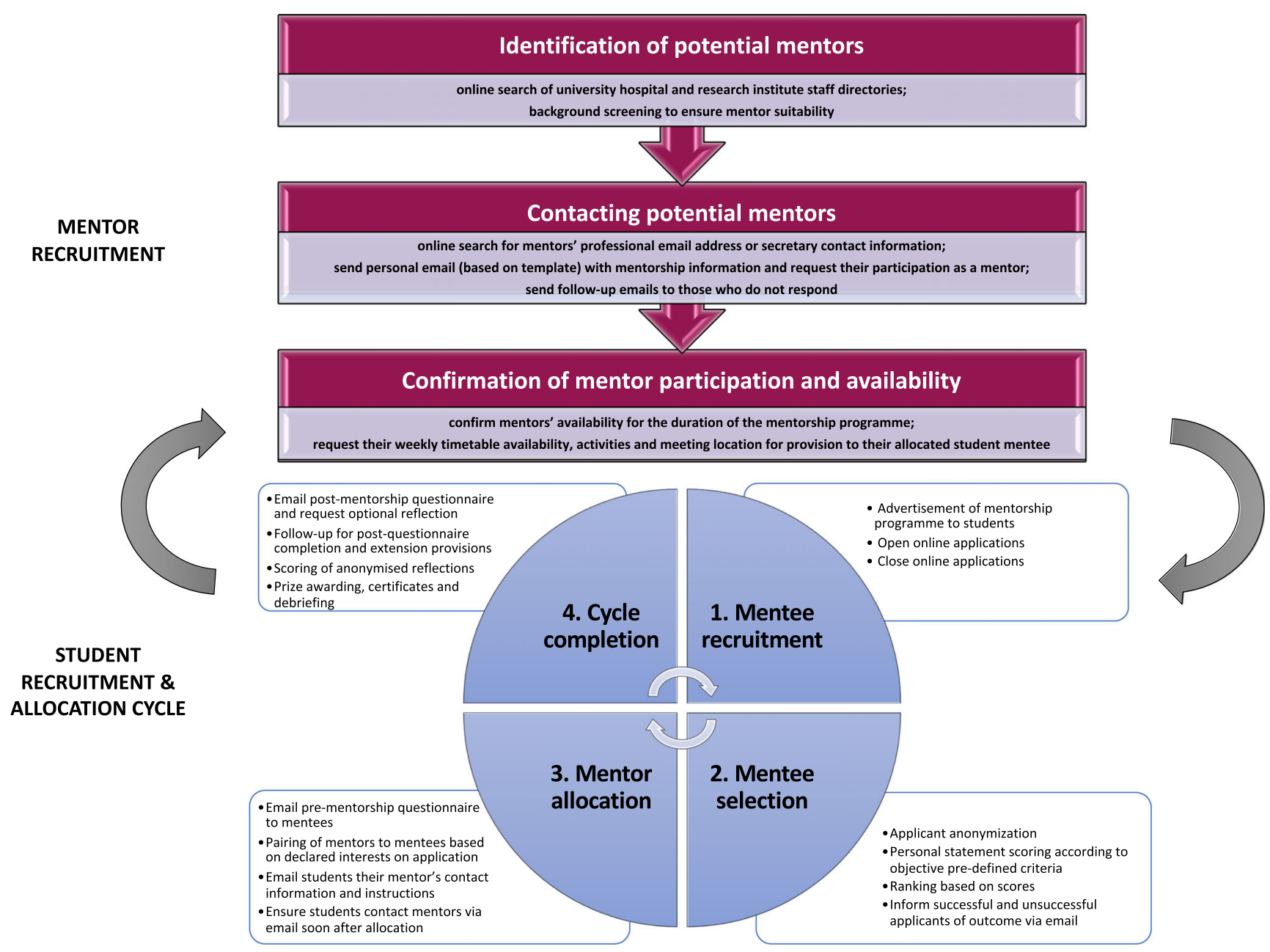

Fig. 1 Structured model for setting up a student mentorship programme through a student interest group outlining the process of mentor recruitment and the student allocation cycle 
The pre-mentorship questionnaire compromised of nine questions: six on a five-point Likert scale, two multiple choice and one free text response; whereas the postmentorship questionnaire compromised of 17 questions: seven on a five-point Likert scale: six identical to prementorship questionnaires, four multiple choice and six free text response. The sign-up application (Appendix 2) gathered information pertaining to students' demographics, including their year of study, as well as their oncological specialty and subject of interest using multiple choice and free response questions.

\section{Comparisons}

We compared responses across student demographics including gender, medical school and year of study. We also compared responses across different specialty of interest (i.e. medical, clinical/radiation or surgical oncology) and subject (e.g. gastrointestinal, gynaecological, haematological cancers etc.) of mentoring placement. Finally, we compared students' perceived oncology-related interest and knowledge pre- and postmentorship.

\section{Outcomes}

The effectiveness of the mentorship programme as an educational, networking and motivational tool was measured by assessing for a significant change $(p<0.05)$ in students' pre-/post-mentorship responses to Likert scale questions in addition to evaluating free text responses.

\section{Procedures to Minimize Bias}

Questionnaires were piloted in a small group of medical students before being reviewed and launched to ensure questions were unambiguous and phrasing did not generate responder bias.

\section{Data Collection}

All surveys were conducted via a standardised, webbased, data collection form (Google Form, Google, Alphabet Inc.). Responses were saved to a passwordprotected Excel file. Regarding free text responses (qualitative data), K.R. proceeded to a pilot thematic analysis; this resulted in discrete thematic axes. These thematic axes were revised by the senior author of the study to ensure data accuracy and any discrepancy was resolved through discussion.

\section{Statistical Analysis}

Statistical analysis was completed on IBM SPSS Statistics software for Mac, Version 26. Descriptive statistics were used to analyse demographics, student interest and feedback. Following assessment of data distributions, we used Wilcoxon signed-rank (WSR) test for paired associations supplemented by Mann-Whitney $U$ (MWU) test for ineffectively paired groups as determined by Spearman correlation coefficient (one-tailed). $p$ value less than 0.05 was considered as statistically significant.

\section{Results}

\section{Demographics}

\section{Undergraduate Oncology Societies}

Forty-two medical schools, including 20 undergraduate oncology societies, were contacted for joining the study (Supplementary Table 1). In addition to BL, five undergraduate oncology societies agreed to participate, though only two successfully established a mentorship programme including Kings College London (KCL) and University of Birmingham Medical School (UBMS) Oncology Societies. The three societies that did not succeed in establishing a mentor programme either withdrew interest due to time restraints of committee members, postponed the programme for the next academic year or cancelled the programme before it began due to coronavirus disease 2019 (COVID-19) lockdown measures and concerns. Three mentorship allocation cycles were carried out successfully at $\mathrm{BL}$, one at $\mathrm{KCL}$ and one at UBMS.

\section{Mentors}

Out of a total of 124 potential mentors contacted and asked to participate in the mentorship programme across all three NHS Foundation Trusts, only 29 (23.4\%) agreed to participate. Table 1 shows a breakdown of mentors' specialties, subspecialties and NHS Trust affiliation.

\section{Mentees}

We received 79 applications out of which 43 (54\%) students were accepted onto the programme by ranking high enough to secure a mentor, completing the pre-mentorship questionnaire, and 30 (70\%) successfully completed the mentorship, responding to the post-mentorship questionnaire. Table 2 summarises students' demographics. Eleven (36.7\%) students were mentored by medical oncologists, $10(33.3 \%)$ were mentored by clinical/radiation oncologists and $9(30 \%)$ by 
Table 1 NHS Trust affiliation, specialty and subspecialty of all contacted $(n=124)$ and confirmed $(n=29)$ mentors

\begin{tabular}{|c|c|c|}
\hline & Contacted Mentors ${ }^{\mathrm{a}}$ & Confirmed Mentors ${ }^{\mathrm{a}}$ \\
\hline \multicolumn{3}{|l|}{ NHS Foundation Trust } \\
\hline Barts Health & $36(29.0)$ & $12(41.4)$ \\
\hline University Hospitals Birmingham & $49(39.5)$ & $13(44.8)$ \\
\hline King's College Hospital & $39(31.5)$ & $4(13.8)$ \\
\hline \multicolumn{3}{|l|}{ Specialty } \\
\hline Medical Oncology & $56(45.5)$ & $11(37.9)$ \\
\hline Clinical/Radiation Oncology & $29(23.6)$ & $8(27.6)$ \\
\hline Surgical Oncology & $31(24.4)$ & $10(34.5)$ \\
\hline Other* & $7(5.7)$ & - \\
\hline \multicolumn{3}{|l|}{ Subspecialty ${ }^{\mathrm{b}}$} \\
\hline Bone cancer & $1(0.8)$ & - \\
\hline Brain cancer & $5(4.0)$ & $2(6.9)$ \\
\hline Breast cancer & $40(32.3)$ & $7(24.1)$ \\
\hline Colorectal cancer & $13(10.5)$ & $6(20.7)$ \\
\hline Gastrointestinal cancer & $21(16.9)$ & $4(13.8)$ \\
\hline Germ cell tumours & $3(2.4)$ & - \\
\hline Gynaecological cancer & $15(12.1)$ & $3(10.4)$ \\
\hline Haematological cancer & $7(5.7)$ & $1(3.5)$ \\
\hline Head and neck cancer & $8(6.5)$ & - \\
\hline Hepatobiliary cancer & $8(6.5)$ & $1(3.5)$ \\
\hline Lung cancer & $26(21.0)$ & $6(20.7)$ \\
\hline Lymphoma & $11(8.9)$ & $3(10.4)$ \\
\hline Melanoma & $4(3.2)$ & $2(6.9)$ \\
\hline Neuroendrocine cancer & $5(4.0)$ & $2(6.9)$ \\
\hline Neurological cancer & $4(3.2)$ & - \\
\hline Paediatric cancer & $2(1.6)$ & $1(3.5)$ \\
\hline Sarcoma & $9(7.3)$ & $5(17.2)$ \\
\hline Skin cancer & $9(7.3)$ & $3(10.4)$ \\
\hline Teenager and young adult cancer & $2(1.6)$ & - \\
\hline Urological cancer & $31(25.0)$ & $8(27.6)$ \\
\hline
\end{tabular}

${ }^{a}$ Data given as number of mentors $(\%)$

${ }^{\mathrm{b}}$ One or more subspecialties per mentor

* Other specialties included cardiology $(n=1)$, haematology $(n=3)$, palliative medicine $(n=2)$ and pneumonology $(n=1)$ cancer specialists

surgical oncologists. Most students met with their mentor on three occasions which was also the median number of mentormentee meetings $(I Q R=2)$.

\section{Student Interest}

Table 3 captures students' self-reported interest in different oncology sub-specialties and fields. Most students were interested in medical oncology $(78.5 \%)$ and academia/ research $(68.4 \%)$ followed by surgical $(64.6 \%)$ and clinical/radiation (57\%) oncology. The most popular fields of interest were haematological (81\%), lung (72.2\%) and gastrointestinal cancers $(70.9 \%)$, while urological cancers $(43.0 \%)$ gathered the least interest.

\section{Impact of Mentorship Programme}

The mentorship programme generated a statistically significant improvement in students' knowledge of the multidisciplinary team $(3.2$ vs. $4.0 / 5, p<0.001)$ as well as the role of medical (3.1 vs. $4.0 / 5, p<0.001)$, surgical (2.8 vs. $3.4 / 5, p=0.006)$ and clinical oncologists $(2.9$ vs. $3.8 / 5, \mathrm{p}<0.001)$ and their involvement in academia/research (3.2 vs. 4.0/5, $p=0.001)$ (Table 4). Mentees' interest in oncology remained unchanged.

\section{Other Student-Reported Benefits (Qualitative Feedback)}

Mentees reported several additional benefits from the mentorship programme in free text responses. We categorised those 
Table 2 University affiliation, year of study and gender of all applicants $(n=79)$ and mentees who completed the mentorship $(n=30)$

\begin{tabular}{lll}
\hline & Total applicants $^{\mathrm{a}}$ & Mentees $^{\mathrm{a}}$ \\
\hline University & & \\
Barts and the London & $50(63.3)$ & $16(53.3)$ \\
Birmingham University & $14(17.7)$ & $10(33.3)$ \\
King's College London & $15(19.0)$ & $4(13.3)$ \\
Year of study & & $7(23.3)$ \\
Year 1 & $28(35.4)$ & $8(26.7)$ \\
Year 2 & $21(26.6)$ & $10(33.3)$ \\
Year 3 & $19(24.1)$ & $4(13.3)$ \\
Year 4 & $7(8.9)$ & $1(3.3)$ \\
Intercalating & $4(5.1)$ & $10(33.3)$ \\
Gender & & $20(66.7)$ \\
Male & $24(30.4)$ & \\
Female & $55(69.6)$ &
\end{tabular}

${ }^{\mathrm{a}}$ Data given as number of students $(\%)$

into certain thematic axes stated on Table 5. Moreover, 28 (93.3\%) students believed that this programme has made them a better medical student or future doctor and 29 (96.7\%) reported that they would have chosen to do it again.

\section{Discussion}

\section{Findings}

The mentorship aimed to increase medical students' exposure of oncology specialties. Results demonstrate a statistically significant increase in students' self-reported knowledge surrounding

Table 3 Declared specialty and field of interest of all applicants $(n=79)$ and mentees who completed the mentorship $(n=30)$

\begin{tabular}{lll}
\hline & Total applicants & \\
\hline Specialty of interest & Mentees $^{\mathrm{a}}$ \\
Medical oncology & & \\
Clinical/radiation oncology & $62(78.5)$ & $25(83.3)$ \\
Surgical oncology & $45(57.0)$ & $18(60.0)$ \\
Academia/research in oncology & $51(64.6)$ & $16(53.3)$ \\
Field of interest & $54(68.4)$ & $24(80.0)$ \\
Breast cancers & & \\
Gastrointestinal cancers & $52(65.8)$ & $17(56.7)$ \\
Gynaecological cancers & $56(70.9)$ & $22(73.3)$ \\
Haematological cancers & $43(54.4)$ & $14(46.7)$ \\
Head and neck cancers & $64(81.0)$ & $23(76.7)$ \\
Lung cancers & $44(55.7)$ & $14(46.7)$ \\
Urological cancers & $57(72.2)$ & $22(73.3)$ \\
\hline
\end{tabular}

${ }^{\text {a }}$ Data given as number of students (\%)

${ }^{\mathrm{b}}$ One or more selected by students all oncology specialties, the multidisciplinary team and cancer research regardless of their allocated mentor's specialization. Mentees report gaining valuable clinical experience and communication skills by observing the doctor-patient relationship and the breaking of bad news. They also learned more about the management of cancer patients and became inspired and motivated to pursue a career in oncology. Clearly, there is no lack of interest amongst students who are evidently drawn to all oncology specialties including academia and research, and are willing to engage in extracurricular teaching amongst their busy schedules. No increase in student interest in oncology was observed post-mentorship as students who applied for the programme already had a strong interest in oncology from the start. Poor mentor, and placement, availability are significant factors that limit undergraduate medical students' exposure to oncology as demonstrated by low mentor uptake (23.4\%) to participate in this programme which was most pronounced at KCL where only four out of 39 contacted professionals agreed to become mentors. Differences in mentor availability across insitutions could potentially be explained by the variation in service demands in geographical regions, with physicians based at high-demand oncology centres less likely to be able to dedicate time to this type of extracurricular teaching.

\section{Significance of Findings}

The growing global demand for oncologists to join the workforce underscores the necessity of early undergraduate oncology teaching. Nationally, students advocate for more clinical exposure to oncology, increased teaching hours, more diverse coverage of cancer topics and more clinical skills teaching focusing on breaking bad news and communicating with terminally ill patients. Our findings address these issues and are consistent with previous research showing that early mentorships significantly impact career selection, career success, research productivity and student wellbeing whilst improving academic inclusivity of students from traditionally underrepresented backgrounds and narrowing the sex gap [16, 17, 25-32]. We also demonstrate the effectiveness of student-led societies in increasing student accessibility to mentors, ultimately serving as an important motivational, networking and educational resource.

\section{Recommendations}

Our findings testify to the value of undergraduate societies in creating student to faculty connections which in turn improve students' career prospectus, research productivity, but also their wellbeing, since effective communication skills have been shown to be a cost effective way of preventing physician burnout [33-35]. Increasing students' oncology exposure is a compelling strategy to prevent specialty attrition by inspiring a future generation of holistically qualified oncologists who are interested in spearheading laboratory and clinical research innovations 
Table 4 Comparison of mentees' responses from pre- and postmentorship questionnaires $(n=$ 30)

\begin{tabular}{llll}
\hline Question & $\begin{array}{l}\text { Pre- } \\
\text { mentorship }^{\mathrm{a}}\end{array}$ & $\begin{array}{l}\text { Post- } \\
\text { mentorship }^{\mathrm{a}}\end{array}$ & value $^{\mathrm{b}}$ \\
\hline $\begin{array}{l}\text { Rate your interest in oncology } \\
\text { Rate your knowledge of the following: }\end{array}$ & $4.7 \pm 0.5$ & $4.7 \pm 0.5$ & 0.738 \\
$\quad \begin{array}{l}\text { Members of the multidisciplinary team in oncology } \\
\quad \text { services }\end{array}$ & $3.2 \pm 0.6$ & $4.0 \pm 0.8$ & $<0.001^{*}$ \\
$\begin{array}{l}\text { The role of medical oncologists } \\
\text { The role of surgical oncologists } \\
\text { The role of clinical oncologists }\end{array}$ & $3.1 \pm 0.8$ & $4.0 \pm 0.8$ & $<0.001^{*}$ \\
The involvement of oncologists in academia/research & $2.8 \pm 0.9$ & $3.4 \pm 1.1$ & 0.006 \\
\end{tabular}

${ }^{\text {a }}$ Data is reported as the mean value of the Likert score \pm standard deviation

${ }^{\mathrm{b}} p$ value obtained from WSR test analysis between pre- and post-mentorship questionnaires

*Inneffective pairing as determined by Spearman correlation coefficient (one-tailed); $p$ value confirmed on MWU test analysis between pre- and post-mentorship questionnaires
[36-38]. Hence, we advocate for more widespread adoption and proactive use of student-led oncology societies in UK medical schools. Agarwal et al. at Boston University School of Medicine, provides a detailed model for other medical schools to initiate their own student oncology societies [24]. Further to this, our report provides a structured model for setting up mentorship programmes through student interest groups (Fig. 1).

\section{Strengths}

To our knowledge, this is the first UK-reported data on the value of oncology mentoring for undergraduate medical

Table 5 Mentees' free text responses to qualitative feedback in postmentorship questionnaire $(n=30)$

\begin{tabular}{lc}
\hline Question & Mentees $^{\mathrm{a}}$ \\
\hline What is the most important thing you gained from this programme? \\
Clinical experience & $10(33.3)$ \\
Communication skills & $9(30.0)$ \\
Learn about cancer patient management & $5(16.7)$ \\
Connect with mentors & $4(13.3)$ \\
Familiarise with breaking bad news & $4(13.3)$ \\
Insight into multidisciplinary team & $4(13.3)$ \\
Insight into research (including clinical trials) & $4(13.3)$ \\
Inspired and motivated & $3(10.0)$ \\
Observe doctor-patient relationship & $3(10.0)$ \\
Research opportunity & $3(10.0)$ \\
Academic, research or career advice & $3(10.0)$ \\
Insight into oncologists' work & $2(6.7)$ \\
Confirm career aspiration & $1(3.3)$ \\
Consolidate textbook learning & $1(3.3)$ \\
\hline
\end{tabular}

${ }^{\text {a }}$ Data given as number of students (\%)

${ }^{\mathrm{b}}$ One or more responses per student students in addition to being the first UK report of an undergraduate oncology society-led mentorship initiative. The strengths of this study include the multi-institutional representability of findings across several medical schools, and the variety of oncological specialties and subspecialties examined, providing valuable insight into students' interests and the benefits of oncology mentoring in different settings.

\section{Limitations}

Limitations to this study include limited sample size, largely due to restricted mentor availability. Also, those are results from a pilot study where questionnaire validation was not possible. Increases in students' self-reported knowledge of oncology post mentorship, albeit corroborated by qualitative feedback to open response questions, was not validated by an objective method of assessment and therefore positive changes could have been influenced by response acquiescence or acceptance bias which lead students to provide a higher estimate of their knowledge in the post-mentorship questionnaire.

\section{Future Endeaveours}

We plan to introduce this mentorship programme nationally across all UK universities. This would allow a larger sample size and increase the amplitude of our results, allowing subgroup analysis by university, allocated mentorship specialty and subspecialty. Organising 3 mentorship cycles per academic year at each university would also aid in increasing mentee capacity. Enabling students to rotate on several specialties would provide a more holistic experience, while providing students with an outcome-based logbook would benefit them in structuring their learning. Extending students' placement is also desirable according to mentees' feedback in free text responses. Measuring students' knowledge by an objective assessment, such as a multiple-choice question test, before and after the 
programme would have been a better means to assess improvements in oncology knowledge. Long-term effects of such mentorship programmes on influencing students' specialty selection can be investigated by following up mentees' specialty training pathway in the future. Further research into understanding the motivations of mentors, their reasons for participating in the programme as well as any issues that may discourage their participation may help address the obstacles faced with mentor recruitment and allow for broadening of the programme if more mentors can be recruited.

\section{Conclusion}

In summary, findings herein demonstrate the effectiveness of undergraduate oncology mentoring as an educational, networking and motivational tool with medical student mentees reporting a statistically significant increase in self-reported knowledge in all areas of oncology examined. Students' interest and desire to engage in oncology research and clinical exposure is largely unmet by restricted mentor, and placement, availability. Further efforts should be made to increase oncology-related placement availability, teaching exposure and research opportunities for medical students within undergraduate medical curricula and extracurricular settings. Student societies are a valuable asset in cultivating student interest in oncology due to their ability to connect students to faculty members thus increasing students' accessibility to mentors. Further research should focus on developing an optimal structure for mentorships and evaluating the long-term outcomes of such educational initiatives.

Supplementary Information The online version contains supplementary material available at https://doi.org/10.1007/s13187-020-01919-7.

Availability of Data and Materials The questionnaires used and analysed during the current study are available from the corresponding author on reasonable request.

Authors' Contributions K.R. has contributed in the conception and design of the work, data collection, data analysis and interpretation, drafting the article and final approval of the version to be published. A.W. has contributed in data collection and final approval of the version to be published. S.H. has contributed in data collection and final approval of the version to be published. A.S. has contributed in data collection and final approval of the version to be published. C.C. has contributed in data collection and final approval of the version to be published. M.S. has contributed in data collection and final approval of the version to be published. T.F.W. has contributed in data collection and final approval of the version to be published. A.A.C. has contributed in data collection and final approval of the version to be published. S.P./A.P./M.C.S. have contributed equally in the design of the work, data interpretation, drafting the article and final approval of the version to be published.

\section{Compliance with Ethical Standards}

Competing Interests The authors declare that they have no competing interests.
Ethical Approval This study did not require ethical approval as it was held as part of an extracurricular teaching programme organised by undergraduate oncology societies of UK medical schools.

Code Availability Not applicable.

Consent to Participate Not applicable.

Consent to Publish Not applicable

\section{Appendix 1 Template email for mentor recruitment}

Dear Dr. [insert potential mentor's name],

I am contacting you on behalf of [insert oncology society name], a student-led society for medical students at [insert medical school name]. Our aim is to help medical students engage with oncology and increase awareness of the opportunities for research and clinical practice in this field.

We are organising a mentorship scheme to allow medical students to gain more exposure and insight into oncology from an early stage in their training. Students will be able to shadow oncologists in clinic, hospital and research settings with aim to cover the following four domains:

- Medical oncology

- Clinical oncology

- Surgical oncology

- Academic/clinical research oncology

Students will apply formally for this scheme, applications will be screened, and students will be assigned to mentors based on compatibility of interests.

We would like to ask if you would be willing to take on 1-2 students as your mentees for a period of 6 weeks sometime between [insert months and year over which mentorship cycle with take place]. Mentees and mentors may choose to maintain their working relationship after this 6-week period. We hope interested students may even get the opportunity to participate in research.

If you are interested in being a mentor, please reply to this email and I can forward you further details. We will need your timetable availability for a 6 -week period and a contact number for students to get in touch with you.

We would be very grateful for your help in this project.

Please do not hesitate to contact me if you have any questions.

Kind regards,

[insert full name of committee member mentorship coordinator].

[insert role of committee member in named oncology society] 


\section{Appendix 2 Mentorship sign-up student application}

\section{Oncology Mentorship Scheme Sign Up}

Our oncology society has organised a mentorship scheme to allow medical students to gain exposure into the different fields of oncology.

This mentorship scheme aims to achieve the following outcomes:

1) Increase awareness of the different career pathways in oncology.

2) Allow students to observe the daily work carried out by oncologists in clinic, hospital, and laboratory setting.

3) Encourage students to pursue a career in oncology as a clinician and/or researcher. 4) Encourage a working relationship between mentors and interested students who may be able to get involved in clinical or laboratory research projects.

Students will be allocated to mentors based on field of interest. Students will be responsible to contact their mentor and try to arrange times to meet and shadow them over a 6-week period. Students are expected to meet with their mentor on 3 occasions, however, it may be possible to maintain contact with mentors after this period and potentially collaborate on research projects.

Mentors are based at the medical school's associated NHS Foundation Trust Hospitals. * Required

1. Due to the nature of this mentorship, student mentees are required to be enrolled as medical students at the University. Please confirm that you are a medical student. *

Mark only one oval.

$\bigcirc$ Yes, I am currently enrolled as a medical student (this includes intercalating students)

No, I am not enrolled as a medical student

2. Full Name (as you would like to appear on certificate) *
8. Please write a short statement ( $<250$ words) explaining why you are interested in this mentorship scheme. *

You may write about your previous commitment to oncology or why you think you would be able to demonstrate consistent involvement to the mentorship scheme. Initiative in contacting mentors and ability to maintain a working relationship are desired qualities. This statement will be used in shortlisting
successful applicants. Due to limited mentor availability we cannot guarantee mentor allocation to all successt

9. I am a subs-paying member *

Due to limited mentor availability only applications from subs-paying members will be considered.

Mark only one oval.

Yes

No

10. Mobile number *

Will be used to facilitate communication with mentor.

11. I would like to join the Oncology Society mailing list *

Mark only one oval.

$\bigcirc$ Yes

No

Already joined

3. Univerisity email * 


\section{Appendix 3 Pre-mentorship questionnaire}

\section{Pre-Mentorship Questionnaire}

Please answer the following questions as accurately and honestly as possible.

Your answers will help us improve the scheme for next year. * Required

1. Email address *

2. Full name *

3. Rate your interest in oncology before starting the mentorship scheme * Mark only one oval

$\begin{array}{lllll}1 & 2 & 3 & 4 & 5\end{array}$

I am not interested $\square \square \square$ I am very interested

4. Rate your knowledge of: members of the multidisciplinary team in oncology services *

Mark only one oval.

\begin{tabular}{lllllll}
1 & 2 & 3 & 4 & 5 \\
I know very little & $\bigcirc$ & $\bigcirc$ & \\
\hline I know a lot
\end{tabular}

9. What is the main reason that you applied for this scheme? *

Mark only one oval.

Generally learn more about oncology

Experience oncology to see if it suits you as a specialty

Network with a mentor who you may be able to work with in the future (e.g. on research projects)

$\checkmark$ See interesting patient cases and get more clinical experience

To build your CV

To demonstrate your interest in this field for future job/trainee applications

Other:

10. Do you have any concerns before starting the mentorship scheme? * Please let us know if something could be done differently to address these either now or for next year.

11. How did you learn about the mentorship scheme? *

Mark only one oval.
Mailing list
Facebook
$\longrightarrow$ Instagram
Through a friend
Other:

12. I consent to my answers being used for research purposes. For more information contact the organising team. *

Check all that apply.

$\square$ Yes 
J Canc Educ (2022) 37:1053-1065

1063

Appendix 4 Post-mentorship questionnaire.

Post-Mentorship Questionnaire

Please answer the following questions as accurately and honestly as possible.

Your answers will help us improve the scheme for next year.

10. What is the most important thing you gained from this programme? *

1. Email address *

2. Name *

11. Do you think this programme has made you a better medical student or a better future doctor?

Mark only one oval.

3. On how many occasions did you meet with your mentor or a member of their team? *

Yes

No

Maybe

4. Rate your interest in oncology after completing the mentorship scheme *

Mark only one oval.

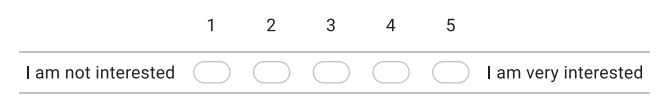

5. Rate your knowledge of: members of the multidisciplinary team in oncology services *

Mark only one oval.

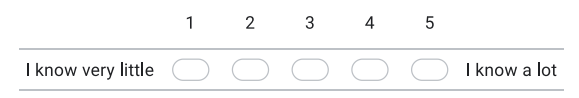

Reflection

12. How beneficial/useful did you find the reflection component? *

Mark only one oval.

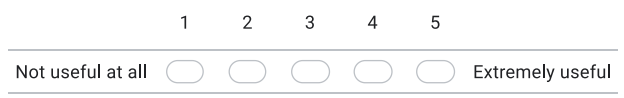

13. Should we continue the reflection component next year? *

Keep in mind reflections may be included in your portfolio and may be beneficial in your future applications. They are also a good way to remember what you did if you need to recall this information in the future (egg. for a personal statement)

Mark only one oval.

Yes

No

Maybe

Springer 


\section{Feedback}

14. What do you think worked well in the programme? What was the best part? *

16

17. Having experienced the programme now and knowing what it is like, would you have chosen to do it again? *

Mark only one oval.

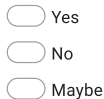

Open Access This article is licensed under a Creative Commons Attribution 4.0 International License, which permits use, sharing, adaptation, distribution and reproduction in any medium or format, as long as you give appropriate credit to the original author(s) and the source, provide a link to the Creative Commons licence, and indicate if changes were made. The images or other third party material in this article are included in the article's Creative Commons licence, unless indicated otherwise in a credit line to the material. If material is not included in the article's Creative Commons licence and your intended use is not permitted by statutory regulation or exceeds the permitted use, you will need to obtain permission directly from the copyright holder. To view a copy of this licence, visit http://creativecommons.org/licenses/by/4.0/.

\section{References}

1. Ahmad AS, Ormiston-Smith N, Sasieni PD (2015) Trends in the lifetime risk of developing cancer in Great Britain: comparison of risk for those born from 1930 to 1960. Br J Cancer 112:943-947

2. Clinical oncology UK workforce census 2017. Clin Oncol 2017:41

3. Erikson C, Salsberg E, Forte G, Bruinooge S, Goldstein M (2007) Future supply and demand for oncologists: challenges to assuring access to oncology services. J Oncol Pract 3:79-86

4. Mattes MD, Patel KR, Burt LM, Hirsch AE (2016) A nationwide medical student assessment of oncology education. J Cancer Educ Off J Am Assoc Cancer Educ 31:679-686

5. Dennis KEB, Duncan G (2010) Radiation oncology in undergraduate medical education: a literature review. Int J Radiat Oncol Biol Phys 76:649-655

6. Barton MB, Bell P, Sabesan S, Koczwara B (2006) What should doctors know about cancer? Undergraduate medical education from a societal perspective. Lancet Oncol 7:596-601

7. Haagedoorn EM, De Vries J, Robinson E (2000) The UICC/WHOCCCE Cancer Education project: a different approach. J Cancer Educ Off J Am Assoc Cancer Educ 15:204-208

8. George M, Mandaliya H, Prawira A (2017) A survey of medical oncology training in Australian medical schools: pilot study. JMIR Med Educ 3:e23

9. Neeley BC, Golden DW, Brower JV, Braunstein SE, Hirsch AE, Mattes MD (2019) Student perspectives on oncology curricula at United States medical schools. J Cancer Educ Off J Am Assoc Cancer Educ 34:56-58

10. Oskvarek J, Braunstein S, Farnan J, Ferguson MK, Hahn O, Henderson T, Hong S, Levine S, Rosenberg CA, Golden DW (2016) Medical student knowledge of oncology and related disciplines: a targeted needs assessment. J Cancer Educ Off J Am Assoc Cancer Educ 31:529-532

11. Mann MP (1992) Faculty mentors for medical students: a critical review. Med Teach 14:311-319

12. Sambunjak D, Straus SE, Marušić A (2006) Mentoring in academic medicine: a systematic review. JAMA 296:1103-1115

13. Luckhaupt SE, Chin MH, Mangione CM, Phillips RS, Bell D, Leonard AC, Tsevat J (2005) Mentorship in academic general internal medicine. J Gen Intern Med 20:1014-1018

14. Illes J, Glover GH, Wexler L, Leung ANC, Glazer GM (2000) A model for faculty mentoring in academic radiology. Acad Radiol 7: $717-724$

15. Ramondetta LM, Bodurka DC, Tortolero-Luna G, Gordinier M, Wolf JK, Gershenson DM et al (2003) Mentorship and productivity among gynecologic oncology fellows. J Cancer Educ Off J Am Assoc Cancer Educ 18:15-19

16. DeNunzio N, Parekh A, Hirsch AE (2010) Mentoring medical students in radiation oncology. J Am Coll Radiol 7:722-728

17. Holliday EB, Jagsi R, Thomas CR, Wilson LD, Fuller CD (2014) Standing on the shoulders of giants: results from the radiation oncology academic development and mentorship assessment project (ROADMAP). Int J Radiat Oncol Biol Phys 88:18-24

18. Hirsch AE, Agarwal A, Rand AE, DeNunzio NJ, Patel KR, Truong MT et al (2015) Medical student mentorship in radiation oncology at a single academic institution: a 10-year analysis. Pract Radiat Oncol 5:e163-e168

19. McKee ND, McKague MA, Ramsden VR, Poole RE (2007) Cultivating interest in family medicine. Can Fam Physician 53: 661-665

20. Peota C (2014) Internal medicine incubator. An internal medicine interest group helps students explore career possibilities. Minn Med 97:8-9

21. Jalalat SZ, Hunter-Ellul L, Wagner RF (2013) Medical student dermatology interest groups. Clin Dermatol 31:656-660 
22. Li R, Buxey K, Ashrafi A, Drummond KJ (2013) Assessment of the role of a student-led surgical interest Group in Surgical Education. J Surg Educ 70:55-58

23. Sanderson B, Funston G (2015) A novel international initiative to promote academic oncology amongst medical students. Med Teach 37:98-98

24. Agarwal A, Shah A, Byler S, Hirsch AE (2017) Cultivating interest in oncology through a medical student oncology society. J Cancer Educ Off J Am Assoc Cancer Educ 32:31-34

25. Stamm M, Buddeberg-Fischer B (2011) The impact of mentoring during postgraduate training on doctors' career success. Med Educ 45:488-496

26. Frei E, Stamm M, Buddeberg-Fischer B (2010) Mentoring programs for medical students - a review of the PubMed literature 2000-2008. BMC Med Educ 10:32

27. Thakur A, Fedorka P, Ko C, Buchmiller-Crair TL, Atkinson JB, Fonkalsrud EW (2001) Impact of mentor guidance in surgical career selection. J Pediatr Surg 36:1802-1804

28. Debenham B, Banerjee R, Fairchild A, Dundas G, Trotter T, Yee D (2012) 2009 Canadian radiation oncology resident survey. Int J Radiat Oncol Biol Phys 82:1326-1331

29. Steiner JF, Lanphear BP, Curtis P, Vu KO (2002) Indicators of early research productivity among primary care fellows. J Gen Intern Med 17:854-860

30. Dorrance KA, Denton GD, Proemba J, La Rochelle J, Nasir J, Argyros G et al (2008) An internal medicine interest group research program can improve scholarly productivity of medical students and foster mentoring relationships with internists. Teach Learn Med 20:163-167

31. Zier K, Friedman E, Smith L (2006) Supportive programs increase medical students' research interest and productivity. J Investig Med Off Publ Am Fed Clin Res 54:201-207

32. Rana S, Holliday EB, Jagsi R, Wilson LD, Choi M, Thomas CR et al (2013) Scholastic activity among radiation oncology residents at US academic institutions: a benchmark analysis. J Cancer Educ Off J Am Assoc Cancer Educ 28:541-546

33. Leal-Costa C, Díaz-Agea JL, Tirado-González S, Rodríguez-Marín J, van-der Hofstadt CJ (2015) Communication skills: a preventive factor in burnout syndrome in health professionals. An Sist Sanit Navar 38:213-223

34. Rodríguez-Rey R, Palacios A, Alonso-Tapia J (2019) Training in communication skills, end-of-life care, and coping strategies as the key to preventing burnout in clinicians. Aust Crit Care Off J Confed Aust Crit Care Nurses 32:277-278

35. Darban F, Balouchi A, Narouipour A, Safarzaei E, Shahdadi H (2016) Effect of communication skills training on the burnout of nurses: a cross-sectional study. J Clin Diagn Res JCDR 10:IC01IC04

36. Theodoulou I, Sideris M, Lawal K, Nicolaides M, Dedeilia A, Emin EI, Tsoulfas G, Papalois V, Velmahos G, Papalois A (2020) Retrospective qualitative study evaluating the application of IG4 curriculum: an adaptable concept for holistic surgical education. BMJ Open 10:e033181

37. Sideris M, Papalois A, Theodoraki K, Dimitropoulos I, Johnson EO, Georgopoulou E-M et al (2017) Promoting undergraduate surgical education: current evidence and students' views on ESMSC international wet lab course. J Investig Surg Off J Acad Surg Res 30:71-77

38. Sideris M, Nicolaides M, Theodoulou I, Emin EI, Hanrahan JG, Dedeilia A et al (2020) Student views on a novel holistic surgical education curriculum (iG4): a multi-national survey in a changing landscape. Vivo Athens Greece 34:1063-1069

Publisher's Note Springer Nature remains neutral with regard to jurisdictional claims in published maps and institutional affiliations.

\section{Affiliations}

\section{Kathrine S. Rallis ${ }^{1,2}$ (D) $\cdot$ Anna Wozniak ${ }^{1,2} \cdot$ Sara Hui $^{1,2} \cdot$ Adam Stammer $^{2} \cdot$ Cigdem Cinar $^{3} \cdot$ Min Sun $^{3} \cdot$ Taylor Fulton-Ward ${ }^{3} \cdot$ Alison A. Clarke ${ }^{4} \cdot$ Savvas Papagrigoriadis $^{5} \cdot$ Apostolos Papalois $^{6} \cdot$ Michail Ch. Sideris $^{7}$}

1 Barts Cancer Institute, Queen Mary University of London, London, UK

2 Barts and The London School of Medicine and Dentistry, Queen Mary University of London, London, UK

3 Birmingham Medical School, University of Birmingham, Birmingham, UK
4 Guy's, King's and St Thomas' School of Medicine, King's College London, London, UK

5 International Society for Pelvic Surgery, Athens, Greece

6 Experimental Educational and Research Centre ELPEN, Athens, Greece

7 Women's Health Research Unit, Queen Mary University of London, London, UK 